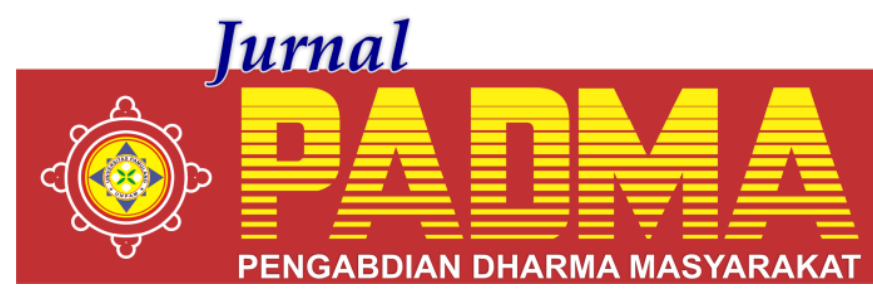

VOLUME I, NOMOR I, JANUARI 2021

\title{
PENYULUHAN WIRAUSAHA UNTUK MENINGKATKAN EKONOMI KELUARGA DENGAN DAUR ULANG BARANG BEKAS DESA PAMEGARSARI KABUPATEN BOGOR
}

\author{
${ }^{1 *}$ Yeti Kusmawati, ${ }^{2}$ Desi Prasetiyani, ${ }^{3}$ Ali Zaenal Abidin, ${ }^{4}$ Elizabeth Tika Kristina Hartuti, \\ 5Muhamad Abid \\ Universitas Pamulang, Tangerang Selatan, Banten, Indonesia \\ *dosen02619@unpam.ac.id
}

\begin{abstract}
Abstrak
Penyuluhan wirausaha home industry untuk meningkatkan ekonomi keluarga dengan daur ulang barang bekas, hadir untuk memberikan pengetahuan, wawasan dan peluang yang sangat potensial dikembangkan, karena bahan bakunya murah dan mudah diperoleh. Tujuan dari penyuluhan wirausaha home industry untuk meningkatkan ekonomi keluarga dengan daur ulang barang bekas agar masyarakat setempat dapat meningkatkan ekonomi keluarga dengan berkreasi, berkarya dan berdaya juang untuk mengubah barang bekas yang tidak bernilai secara ekonomis menjadi barang yang bernilai guna serta bernilai ekonomi tinggi.
\end{abstract}

Kata kunci: Wirausaha

\section{Abstract}

Counseling home industry entrepreneurs to improve the family economy by recycling used goods, is here to provide knowledge, insight and opportunities that are very potential to be developed, because raw materials are cheap and easy to obtain. The purpose of counseling home industry entrepreneurs is to improve the family economy by recycling used goods so that the local community can improve the family economy by creating, working and struggling to convert used goods that are not economically valuable into goods of high value and economic value.

Keywords: Entrepreneurship

\section{PENDAHULUAN}

Pengabdian kepada masyarakat merupakan pelaksanaan pengamalan ilmu pengetahuan, teknologi dan seni budaya langsung pada masyarakat secara kelembagaan melalui metodologi ilmiah sebagai penyebaran Tri Dharma Perguruan Tinggi serta tanggung jawab yang luhur dalam usaha mengembangkan kemampuan masyarakat, sehingga dapat mempercepat laju pertumbuhan tercapainya tujuan pembangunan nasional.

Permasalahan pemenuhan kebutuhan ekonimi mewarrnai kehidupan bermasyarakat. Daya saing yang sangat kompetitif dari masa ke masa menyebabkan tidak semua orang berusia produktif berkessempatan mendapatkan pekerjaan agar berpenghasilan untuk memenuhi kebutuhannya. Untuk masyarakat kalangan menengah ke atas dengan pendapatan yang besar, bukan menjadi masalah besar untuk pemenuhan kebutuhan, namun untuk masyarakat kalangan menengah ke bawah yang berpenghasilan sedikit atau mempunyai penghasilan tidak tetap, kondisi seperti sekarang ini dimana harga barang dan jasa relative naik juga banyaknya kebutuhan yang harus dipenuhi, membuat hidup seakan sangat sulit. Begitu juga dengan masyarakat desa, yang notabene penghasilan keluarga di dapat dari hasil bertani atau berladang, pemenuhan kebutuhan ekonomi atau kebutuhan seharihari hanya mengandalkan hasil kebun atau ladangnya. Sulit bagi masyarakat seperti itu untuk meningkatkan kualitas hidupnya. Untuk memenuhi kebutuhan pokok sandang pangan dan papan masih tergolong sulit, apalagi untuk menuntut ilmu ke jenjang pendidikan lebih tinggi sangat berat, sehingga banyak ditemukan anak putus sekolah dan orang tua yang buta aksara. Kalau keadaan seperti ini terus berlanjut dan terus menambah angka anak putus sekolah maka masa depan mereka juga akan 
terancam. Yang ada diusia anak sekolah banyak yang tidak sekolah karena harus membantu orang tuanya mencari nafkah untuk memenuhi kebutuhan sehari-hari.

Desa Pamegarsari Kec. Parung Kab. Bogor Kecamatan Rumpin Kabupaten Bogor masuk kedalam katagori Desa Madya, mata pencaharian masyarakat desa adalah bertani dan berladang taraf hidup masyarakat masih tergolong menengah ke bawah, jumlah lulusan perguruan tinggi masih tergolong sangat langka, masih banyak siswa putus sekolah dikarenakan ketiadaan biaya serta pengetahuan orang tua mengenai penting nya sekolah sangat minim. Melihat situasi kurangnya pendidikan di desa dan masih banyak ditemukan anak putus sekolah serta para orang tua yang buta aksara, maka para pemuda Desa Ds Pamegarsari Kec. Parung Kab. Bogor, Kecamatan Rumpin, Kabupaten Bogor tergerak mendirikan Taman Belajar Kreatif Ds Pamegarsari Kec. Parung Kab. Bogor (TBK), suatu komunitas yang bertujuan membantu masyarakat desa mendapatkan pendidikan melaui jalur non formal. TBK ini merupakan salah satu alternatif yang dipilih dan dijadikan sebagai ajang proses pemberdayaan masyaraka, maka akan banyak potensi yang dimiliki oleh masyarakat yang selama ini belum dikembangkan secara maksimal. TBK diarahkan untuk dapat mengembangkan potensi-potensi tersebut menjadi bermanfaat bagi kehidupannya. Agar mampu mengembangkan potensi-potensi tersebut, maka diupayakan kegiatan pembelajaran yang diselenggarakan di TBK bervariasi sesuai dengan kebutuhan masyarakat.

Berdasarkan fenomena tersebut para pemuda Desa Ds Pamegarsari Kec. Parung Kab. Bogor Kecamatan Rumpin Kabupaten Bogor menggangas berdirinya komunitas belajar yaitu Taman Belajar Kreatif Ds Pamegarsari Kec. Parung Kab. Bogor (TBK) untuk mewadahi anak-anak putus sekolah dan memberantas buta huruf bagi warga setempat. Taman Belajar Kreatif Ds Pamegarsari Kec. Parung Kab. Bogor diprakarsai berdiri dengan segala keterbatasannya maka untuk kesekretarianatan atau proses kegiatan belajar pun sampai saat ini masih menumpang di Kantor Desa Pamegarsari Kec. Parung Kab. Bogor. Tenaga pengajar juga masih menggunakan tenaga relawan yang memiliki panggilan jiwa untuk berbagi pengetahuan dan pengalaman kepada masyarakat yang masih sangat membutuhkan perhatian dari pemerintahan setempat. Semuanya masih serba terbatas mulai dari tempat belajar, sarana dan prasarana belajar, sumber daya manusia dan fasilitas lainnya.

Fasilitas yang serba terbatas tersebut menjadi salah satu factor kurang maksimalnya transfer pengetahuan atau pengalaman kepada warga Taman Belajar Kreatif Ds Pamegarsari Kec. Parung Kab. Bogor, sehingga setelah menyelesaikan belajarnya, kurang mempunyai daya saing dengan warga masyarakat lainnya yang lulus dari Sekolah Menengah Atas ataupun Perguruan TInggi. Lapangan kerja yang tersedia kurang bisa mewadahi untuk tamatan Taman Belajar Kreatif Ds Pamegarsari Kec. Parung Kab. Bogor, dimana pada akhirnya hanya akan menambah angka pengangguran. Jika tamatan Taman Belajar Kreatif Ds Pamegarsari Kec. Parung Kab. Bogor tidak berkesempatan untuk bersaing memperoleh pekerjaan yang layak, mereka harus dikondisikan untuk mampu mengatasi permasalahannya secara mandiri yaitu dengan cara berwirausaha untuk menciptakan lapangan pekerjaan dirinya sendiri dan orang lain sserta untuk memenuhi kebutuhan ekonomi keluarganya.

\section{METODE}

Metode pelaksanaan dalam kegiatan program pengabdian kepada masyarakat ini diawali dengan melakukan pendekatan kepada ketua Taman Belajar Kreatif Ds Pamegarsari Kec. Parung Kab. Bogor. Surve awal yang dilakukan oleh tim pengusul untuk menjajaki dan mengetahui permasalahan yang ada di internal TBK dan masyarakat Desa Pamegarsari Kec. Parung Kab. Bogor Kecamatan Rumpin Kabupaten Bogor. Dari hasil surve awal melalui wawancara dengan ketua Taman Belajar Kreatif Ds Pamegarsari Kec. Parung Kab. Bogor, disampaikan pada dasarnya keberadaan Taman Belajar Kreatif Ds 
Pamegarsari Kec. Parung Kab. Bogor untuk membantu masyarakat Desa Pamegarsari Kec. Parung Kab. Bogor social dan ekonomi.

Peningkatan ekonomi keluarga akan dapat diwujudkan apabila, 1) anggota keluarga memiliki kesadaran yang mendorong pencapaian peningkatan ekonomi; 2) semua anggota keluarga memiliki perilaku jujur, berkomitmen, terbuka, disiplin, bertanggung jawab serta mampu bekerjasama untuk satu tujuan yaitu meningkatkan perekonomian keluarga; 3) memberdayakan kemampuan atau potensi yang dimiliki keluarga dengan harapan dapan meningkatkan pendapatan keluarga; 4) semua anggota keluarga mampu memanfaatkan alokasi sumber ekonomi keluarga berdasarkan kebutuhan bukan keinginan; dan 5) semua anggota keluarga berkomitmen melakukan pengendalian perekonomian keluarga sebaik-baiknya.

\section{HASIL DAN PEMBAHASAN}

Jadwal pelaksanaan kegiatan secara umum berjalan dengan baik, dan sesuai dengan jadwal yang ditentukan. Hanya saja waktu pelaksaan mundur 1 jam, dikarenakan adanya persipan yang sifatnya insidentil. Pada pertemuan awal saling melakukan perkenalan diri guna mengawasi dengan baik sebuha kegiatan kemasyarakatan. Suasana pertemuan awal bersifat nonformal dan menggunakan pendekatan persuasive dan terbuka. warga diajak berdialog dan berdiskusi dengan teman sebaya. Pertemuan berikutnya selama $45 \times 2$ membahas tentang barang barang yang bisa di daur ulang. Pada pertemuan ini anak dilatih mempergunakan barang bekas. Para warga antusias untuk mengikuti acara . Pertemuan diakhiri dengan perpisahan dan kata penutup dari Ketua RT 01 RT Suarta. Beliau berpesan agar acara tersebut dapat dikembangkan dengan materi lain yang sejenis. Pada pertemuan di hari akhir ,sebelum diadakan evaluasi para fasilitator. Kegiatan ini diajarkan bersama-sama. Satu kelompok terdiri dari 2 - 3 warga.

Materi penyuluhan adalah pelatihan pembuatan pot bunga dari botol minuman. Tujuan: penyuluhan ini adalah memberikan ilmu dan wawasan baru kepada Warga tentang wirausaha dan peluang usaha rumahan, sehingga terbuka pikiran serta tumbuh minat dan motivasi dalam diri mereka untuk berwirausaha. Disamping itu juga diberikan materi tentang prinsip dasar pembuatan, bertujuan agar mitra mengetahui cara pembuatan. Penyuluhan ini disampaikan dalam bentuk ceramah dan tanya jawab kepada peserta dengan adanya penyuluhan tersebut warga segera menemukan ide ide cemerlang untuk barang bekas sekitar yang dapat di manfaatkan guna dapat menghasilkan barang yang memiliki nilai jual yang bermanfaat secara pribadi dan dapat menigkatkan perekonomian warga.

\section{DAFTAR PUSTAKA}

Baron-Donovan, C., Wiener, R. L., Gross., K., \& Block-Lieb, S. 2005. Financial literacy teacher training: A multiple-measure evaluation. Financial Counseling and Planning, 16(2), 63-75.

Bernheim, B. D., Garrett, D. M., \& Maki, D. M. 1997. Education and Saving: The LongTerm Effects of High School Financial Curriculum Mandates. National Bereau of Economic Research. Working Paper 6085.

Blue,L., Grootenboer, P., \& Brimble, M. 2014. Financial Literacy Education in the Curriculum: Making the Grade or Missing the Mark?. International Review of Economics Education, 16, pp. 51-62.

Chen, H., \& Volpe R. P. 1998. An Analysis of Personal Financial Literacy Among College Students. Financial Services Review, 7(2), 107-128.

Pawar, A., Sudan, K., Satini, S., \& Sunarsi, D. (2020). Organizational Servant Leadership. International Journal of Educational Administration, Management, and Leadership, 63-76.

Sunarsi, D., Akbar, I. R., Prasada, D., Kristianti, L. S., Muliani, H. S., Anjayani, N. S., \& Hendra, H. (2020). Pengaruh Kompetensi dan Pengembangan Karir terhadap Kinerja Karyawan pada PT. Berkah Cemerlang di Jakarta. Jurnal Ilmu Komputer dan Bisnis, 11(2), 2465-2472.Dwiastanti, A. 2015. Financial Literacy as the Foundation for Individual Financial Behavior. Journal of Education and Practise, $6(33)$ 